\title{
Flexural Characteristics of Mortar Cement Reinforced with 3D-Printed Polymer
}

\author{
Ahmed Shweiki, M.Talha Junaid, Samer Barakat \\ Department of Civil and Environmental Engineering, College of Engineering, University of Sharjah \\ Sharjah, UAE \\ ashweiki@sharjah.ac.ae; mjunaid@sharjah.ac.ae; sbarakat@sharjah.ac.ae
}

\begin{abstract}
In this research, reinforcement for cement mortars is printed using polymers-thermoplastics on a Fused Deposition Modeling (FDM) 3D printer and its effect on the strength and response of cementitious mortar samples under bending are studied. Two common thermoplastic polymers; Poly Lactic Acid (PLA) and Polyethylene Terephthalate Glycol-Modified (PETG) are used to reinforce mortar beam samples measuring 200x50x50 mm in flexure. For each thermoplastic type, four bar $150 \mathrm{~mm}$ in length and with a plain rectangular cross-section of 10x5 mm were printed and embedded in the specimen and tested under 3-point load flexural load. The samples with PETG reinforcement showed much better flexural behavior than the PLA reinforced samples in terms of ultimate loads and deformations. The average ultimate flexural capacity of the PETG samples is almost double of the PLA samples (11.37 MPa compared to $5.94 \mathrm{MPa}$ ), while the deformation of the PETG samples at ultimate loads reached 3 times the deformation of the PLA samples owing to its higher strength and plastic behavior.
\end{abstract}

Keywords: 3D-printing, FDM process, thermoplastic polymers, reinforcement, mortar, flexure test.

\section{Introduction}

Recent advancement in additive manufacturing (AM) or 3D printing has increased significantly from using new material and new methods [1], to increase in speed and size of printing. Mainly the price of these printers has reduced significantly allowing for more application in fields like dental, medical, robotics, architecture, arts, manufacturing industry, mechanical and civil engineering [2-3]. Although 3D printing in civil engineering has a lot of potentials and several countries have adopted some level of 3D printing technology in civil structures like in UAE-Dubai in the office of the future which is the first office 3D printed, see ref [4]. And in Italy the D.Shape company by Enrico Dini who designed and fabricated a full scale $3 \mathrm{~d}$ printer for concrete and he is printing model structures for many countries in Europe see ref [5]. Also, another great 3D printing structures application is by WinSun company in China which is already commercialized $3 \mathrm{~d}$ printing for homes and up to 3 story houses see ref [6]. And an application in reference [7],is an example of large scale $3 \mathrm{~d}$ printing of structural elements.

However, currently, there are challenges related to the applications of such technologies in large-scale construction [89]. One such challenge is the placement or printing of reinforcement while printing concrete. Nevertheless, the technology exists which allows for different material to be printed using the same nozzle or switching of nozzles for printing a different material. However, this is only available in small-scale applications. Moreover, conventional steel printing technology is highly complicated and expensive [10]. The process of steel printing is powder or weld based while mortar printing usually adopts the Fused Deposition Modelling(FDM) or Fused filament fabrication (FFF) process. These processes are not compatible and therefore their use in printing 3D structural elements is not explored.

Another alternative to conventional steel reinforcement is the use of thermoplastics or polymers to reinforce concrete members [11-12]. Such polymers fibers are currently used in the market to produce fiber reinforced concrete, however, their application to 3D printing in structural elements is very limited. If such 3D printed reinforcement is to be used for structural applications, its properties and the behavior of the composite thus made must be investigated. To this end, this work looks at the use of different 3D printed polymers as reinforcement for OPC mortars. The focus of this paper is to study the flexural response of small-scale prismatic beams reinforced with 3D printed thermoplastic polymers. 


\section{Experimental Program}

\subsection{Materials}

A mortar mix consisting of cement, fly ash and sand was used. The water to binder ratio was 0.343 sand/binder ratio was 0.714 , and fly ash/cement ratio was 0.4. Fly ash was chosen for its workability and its fineness which will improve workability. The mix was tested and the 28day compressive strength and density were 55MPa and 2190 $\mathrm{kg} / \mathrm{m} 3$, respectively. The thermoplastic polymers that were used as a reinforcement were Poly Lactic Acid (PLA) and Polyethylene Terephthalate Glycol-Modified (PETG). These materials were chosen because they are widely used in Fused Deposition Modelling (FDM) 3D printing process.

\subsection{PLA AND PETG Properties}

Compression and tensile tests necessary for the study were conducted on these materials. The tensile tests were done for both thermoplastic polymers using coupon test samples. The details of the samples and the test results are presented in Figure 1 below and the results are tabulated in Table 1. The results reveal that both materials have almost the same ultimate strength but the PETG showed a very large elongation and no sudden failure like PLA. This property resulted in huge differences in flexural behavior of both samples as discussed in the Results section.

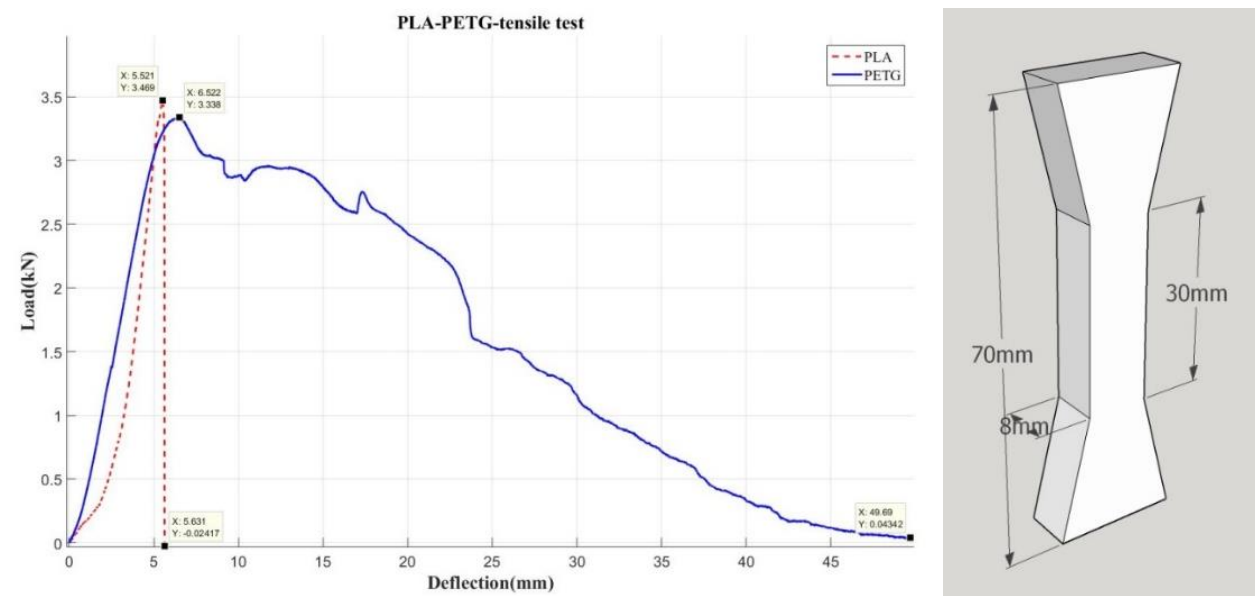

Fig. 1: Tensile test results for thermoplastic polymers(left) and coupon test sample(right).

Table 1: Mechanical properties of PLAand PETG material.

\begin{tabular}{|l|l|l|l|}
\hline material & Density $\left(\mathbf{k g} / \mathbf{m}^{\mathbf{3}}\right)$ & Tensile strength $(\mathbf{M P a})$ & Elongation \% \\
\hline PLA & 1210 & 43.4 & 18.5 \\
\hline PETG & 1270 & 41.7 & 165.5 \\
\hline
\end{tabular}

\subsection{Specimens}

The Reinforcements were printed using a CAM FDM printer utilizing 3D CAD designed rectangular cross-section of $5 \mathrm{~mm}$ width by $10 \mathrm{~mm}$ height and $190 \mathrm{~mm}$ length. Four bars with a total cross-sectional area of $200 \mathrm{~mm} 2$ were placed at a clear spacing of $7.4 \mathrm{~mm}$ between each bar and cover of $5.28 \mathrm{~mm}$. As shown in Figure 2, the specimen size was 200x50x50mm. 


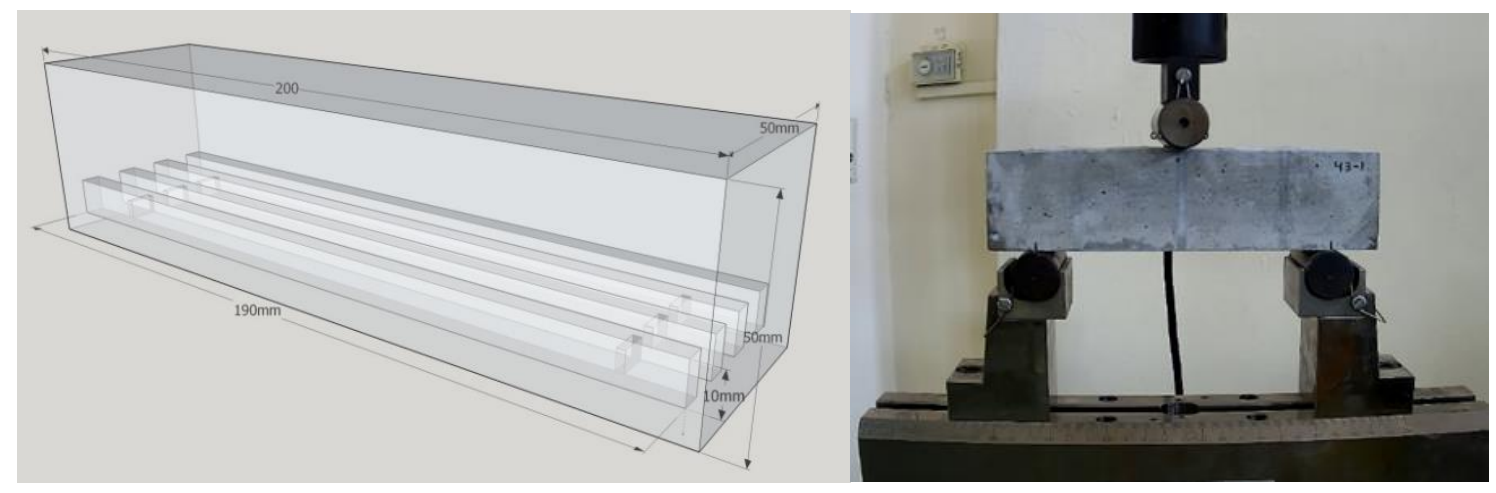

Fig. 2: Schematic of printed reinforcement in mortar prism(left) and center point bending test setup (right).

A total of 6 beams were cast; 3 for each PLA and PETG and tested in flexural in center point bending test. The clear span for each beam was $150 \mathrm{~mm}$ as shown in Figure 2 and the loading rate was $0.005 \mathrm{~mm} / \mathrm{sec}$ applied in displacement control using an Instron 8801 material testing machine.

\section{Results and Discussion}

\subsection{Material Test Results}

As seen from Figure 1, PLA is exhibiting brittle behavior and fails suddenly after maximum load. PLA also has a higher elastic modulus seen by the steeper slope than that of PETG. Nevertheless, the behavior of PETG is quite different from the PLA after maximum load (even though PLA has a slightly higher strength) in such that PETG behaves in a ductile fashion shown in the figure by large deflection after the maximum load is reached.

\subsection{Flexural Test Results}

Test results are plotted in a graph of Load-Deflection as shown in Figure 3 and a zoomed first crack graph is shown in Figure 4.

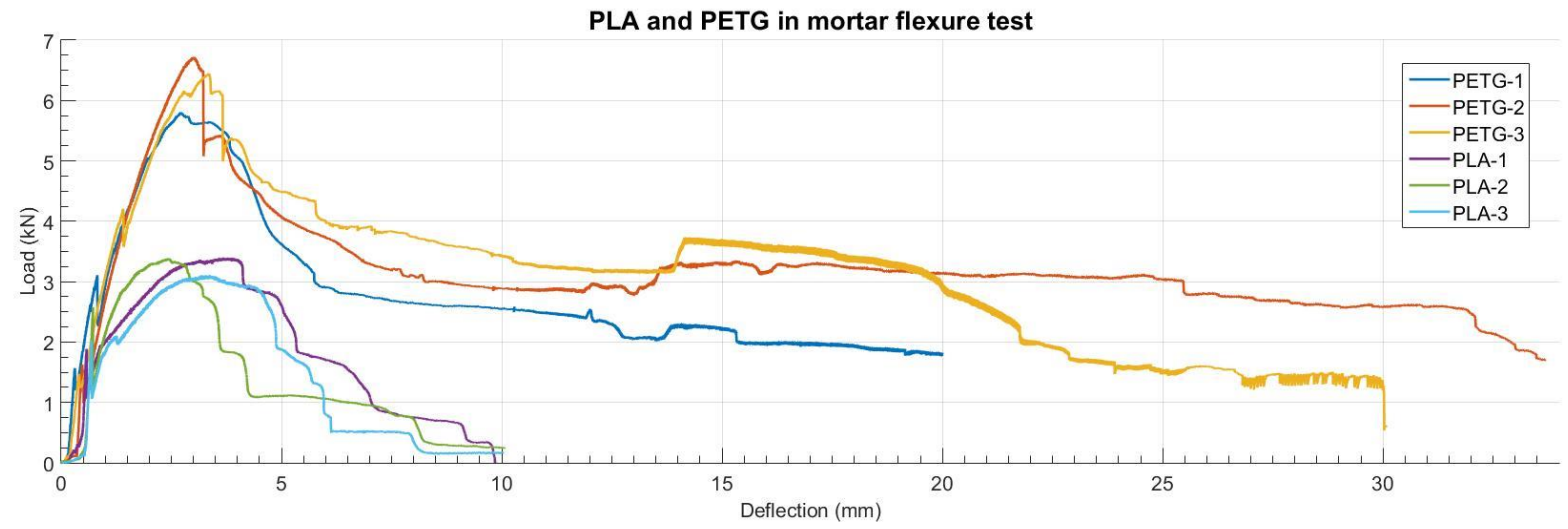

Fig. 3: Load vs deflection curves for all tested specimens.

Looking at the load-deflection results the abrupt change in slope designates the first crack. The graphs of the two materials clearly show the differences in behavior for the materials. The first difference is the load value at first crack as shown in Figure 4 and tabulated in Table 2. PLA-1 to 3 specimens had a higher first crack load with an average value of $2056 \mathrm{~N}$ compared to PETG-1 to 3 specimens which had an average first crack load value of $1563 \mathrm{~N}$. A possible explanation for this behavior may be due firstly to the difference in modulus of elasticity of PLA and PETG. The modulus for PLA as reported by the manufacturer is $3.5 \mathrm{GPa}$ while that for PETG is $2.2 \mathrm{GPa}$. This higher modulus of PLA will provide higher stiffness to the flexural system thus delaying the first crack. Secondly according to the material test results PLA has higher 
tensile strength which will contribute to the higher first crack strength. Thirdly the ductility of PETG will allow the load to be distributed along the sample and reduce the first crack load when compared to the stiff PLA that will resist the load along the sample and provide higher first crack load.

The second difference is in maximum load reached; PETG-1to3 specimens had a much higher maximum load of more than double than that of PLA. As obvious from Figure 3, the PLA is much more brittle than the PETG and therefore once the maximum load is reached, the PLA fails abruptly. The PETG, on the other hand, has a ductile response and undergoes large deformations after peak load and this due to the properties of the PETG itself which is more ductile as per Figure 1 and also the way the $3 \mathrm{~d}$ printing FDM process works as the outer layers of printed lines strain and rupture due to adhesion with the matrix the inner one takes action and resist force and elongates. This provides some strain hardening characteristics to the composite member which is evident in Figure 3.

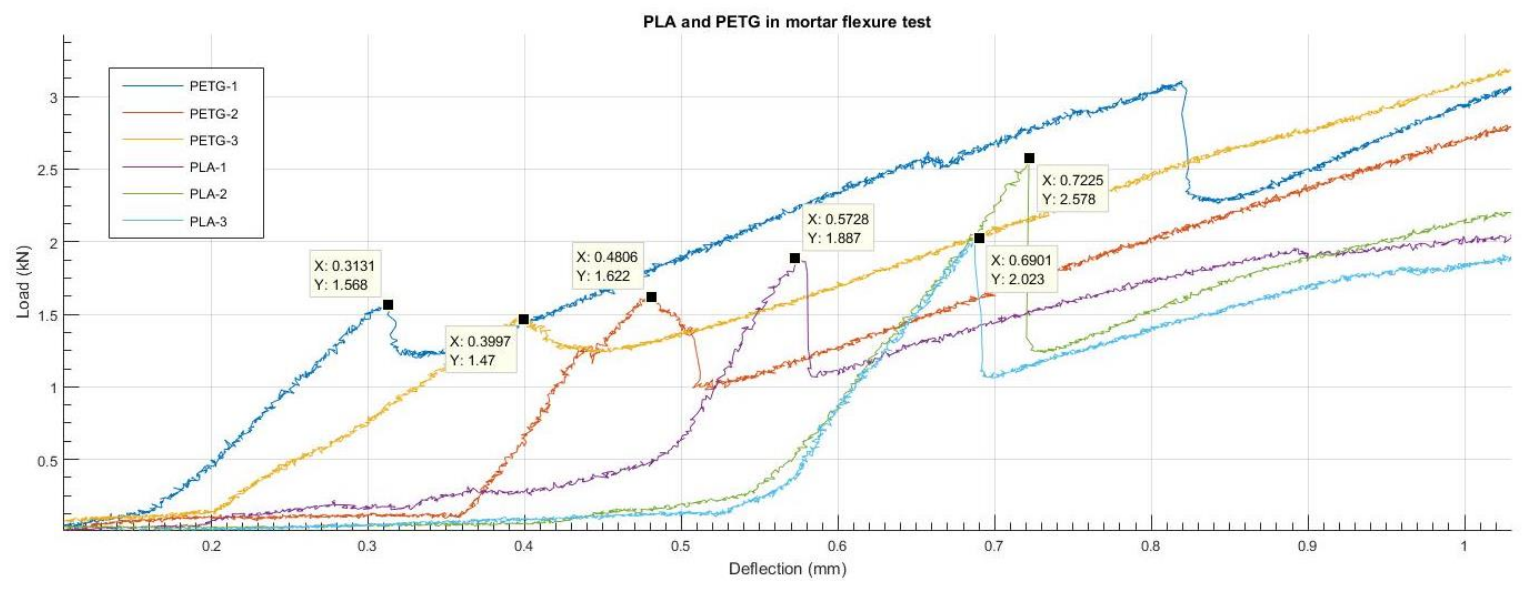

Fig. 4: Close up view of Load-deflection curve showing first crack for all specimens.

Looking at the deformation results, the PLA samples reached around 10mm mid-span deflection, while PETG reached above $30 \mathrm{~mm}$ and still has a load carrying capacity more than the first crack load and not all bars were broken. This again can be explained by the material properties. As evident, the PETG is much more ductile than the PLA and therefore offers larger deflections before failure. This behavior is also evident when the thermoplastic is used in a composite.

Figure 5 below shows the samples after testing. It is noted that most samples failed in flexure but for the PETG-1 and 3, some shear crack were also observed. This, of course, is due to large deformations which redistribute the stresses caused by loading. However, the failure for all tested samples was flexural. Also, all samples experienced large cracks that started at first cracking load and grew as the load was increased up to failure.

Table 2: First crack, maximum load, and flexural strength values.

\begin{tabular}{|l|c|l|l|l|l|l|l|l|}
\hline & \multicolumn{4}{|c|}{ PLA } & \multicolumn{4}{|c|}{ PETG } \\
\hline Sample & $\begin{array}{l}\text { First } \\
\text { crack } \\
\text { load(N) }\end{array}$ & $\begin{array}{l}\text { Max } \\
\text { load } \\
(\mathrm{N})\end{array}$ & $\begin{array}{l}\text { Modulus } \\
\text { of rupture } \\
(\mathrm{MPa})\end{array}$ & $\begin{array}{l}\text { Max } \\
\text { strength } \\
(\mathrm{MPa})\end{array}$ & $\begin{array}{l}\text { First } \\
\text { crack } \\
\text { load(N) }\end{array}$ & $\begin{array}{l}\text { Maximum } \\
\text { load } \\
(\mathrm{N})\end{array}$ & $\begin{array}{l}\text { modulus of } \\
\text { rupture } \\
(\mathrm{MPa})\end{array}$ & $\begin{array}{l}\text { Max } \\
\text { strength } \\
(\mathrm{MPa})\end{array}$ \\
\hline 1 & 1887 & 3392 & 3.4 & 6.1 & 1568 & 5799 & 2.8 & 10.4 \\
\hline 2 & 2578 & 3389 & 4.6 & 6.1 & 1622 & 6722 & 2.9 & 12.1 \\
\hline 3 & 2023 & 3108 & 3.6 & 5.6 & 1470 & 6443 & 2.6 & 11.6 \\
\hline Average & 2056 & 3296 & 3.7 & 5.9 & 1553 & 6321 & 2.8 & 11.4 \\
\hline
\end{tabular}




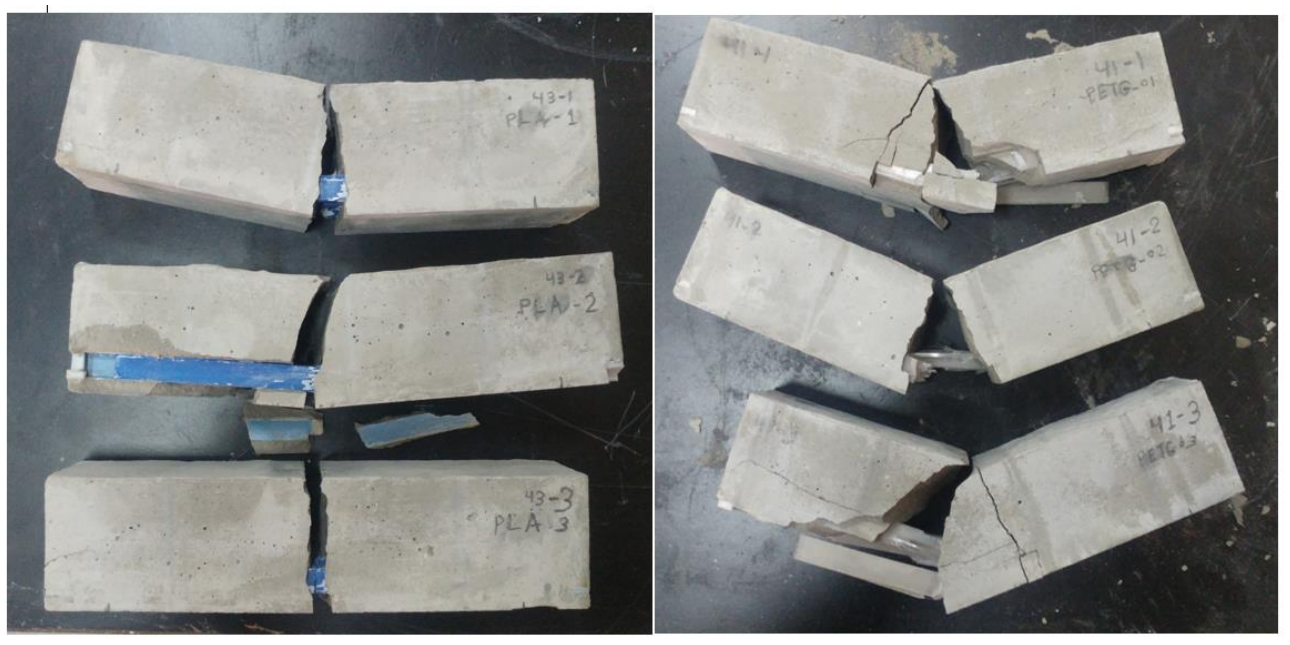

Fig. 5: Failure modes of the tested samples; left PLA right PETG.

The summary of results is tabulated in Table 2 below shows the load at first crack and the maximum load and average values.

The toughness and residual strength parameter were also examined, and area under the load-deflection graph or energy absorbed were calculated for each sample as shown in Figure 6 below and tabulated in Table 3. The area under the curve for PETG deflections was taken only to the $30 \mathrm{~mm}$ mark to be able to compare the results between all the PETG samples. From the calculated areas, it is concluded that PETG has an average toughness value of 91.6J and PLA 16.3J. Thus, PETG is absorbing 5 times the energy absorbed by PLA which gives it a distinct advantage for structural applications.

Table 3: Area under the curve -Absorbed energy for the tested specimens.

\begin{tabular}{|l|l|l|}
\hline & PLA & PETG \\
\hline Sample & Energy $(\mathrm{J})$ & Energy $(\mathrm{J})$ \\
\hline $\mathbf{1}$ & 18.9 & 75.8 \\
\hline $\mathbf{2}$ & 14.8 & 101.9 \\
\hline $\mathbf{3}$ & 15.2 & 97.1 \\
\hline Average & 16.3 & 91.6 \\
\hline
\end{tabular}



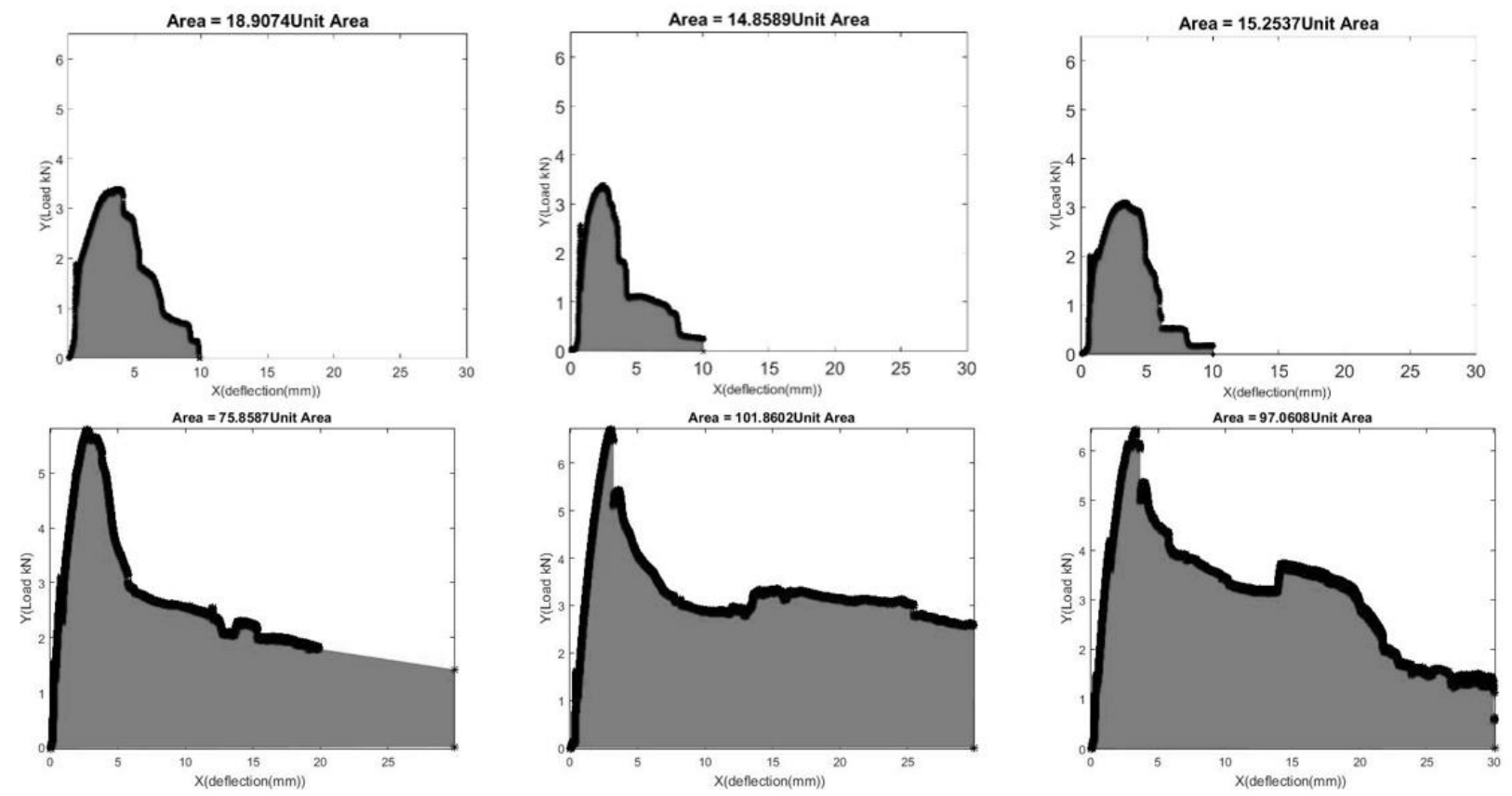

Fig. 6: Area under the curve for each Specimen.

\section{Conclusion.}

The effects of printed reinforcement using polymers-thermoplastics by Fused Deposition Modeling (FDM) 3D printer on the strength and deformation of cementitious mortar samples under bending are studied. Two common thermoplastic polymers; Poly Lactic Acid (PLA) and Polyethylene Terephthalate Glycol-Modified (PETG) are used to reinforce six mortar beam samples measuring 200x50x50 mm tested under 3-point flexural test. For each thermoplastic type, four bar $150 \mathrm{~mm}$ in length and with a plain rectangular cross-section of 10x5 mm were printed and embedded in the specimen. The following conclusions can be drawn from the test results:

1- The samples with PETG reinforcement showed much better flexural behavior than the PLA reinforced samples in terms of ultimate loads and deformations. This was as expected since the PETG material itself exhibits higher ductility than PLA. This ductility is also evident in the composite beams.

2- The average ultimate flexural capacity of the PETG samples is almost double that of the PLA samples while the deformation of the PETG samples at ultimate loads reached 3 times the deformation of the PLA samples.

3- The PETG's high ductility property gave the reinforced mortar a high flexural strength with higher strain hardening properties after the fracture of the mortar. PLA reinforced samples behaved in a brittle manner and provided higher first crack load compared to PETG reinforced samples but failed at lower deflection and load values than PETG reinforced samples.

4- The energy absorbed by the PETG samples was on average 5 times more than the PLA samples also due the properties of PETG and its behavior with concrete. Using 3D printed polymers as reinforcement in mortar can improve the energy absorption significantly.

Given the adaptability of such reinforcement to be printed on site and the enhanced flexural behavior of such cement composites as evident from this initial study is encouraging and requires a more intensive investigation of the adaptableness of such methods in large scale construction. Further tests to be conducted is using different polymer material with higher strength such as Polyester and Polypropylene and Nylon, also the use of fiber reinforced polymers, also Further study to compare the same and different materials with higher and lower strength mortar should be done. 


\section{Acknowledgements}

The author sincerely thanks The graduate's studies department in university of Sharjah and the Emirates Islamic Bank for funding the conference attendance expenses and fees. Also many thanks to Prusa3D.com for suppling the PETG 3D printing material.

\section{References}

[1] J. W. Stansbury and M. J. Idacavage, "3d printing with polymers: challenges among expanding options and opportunities,” Dental Material-By ELSEVIER, vol. 32, no. 1, pp. 54-64, 2016.

[2] J.-Y. Lee, J. An and C. Kai Chua, "Fundamentals and applications of 3D printing for novel materials," Applied Materials Today, vol. 7, no. 1, pp. 120-133, 2017.

[3] X. Wang, M. Jiang, Z. Zhou, J. Gou and D. Hui, “3d printing of polymer matrix composites: A review and prospective," Composites Part B: Engineering-By ELSEVIER, vol. 110, no. 1 february, pp. 442-458, 2017.

[4] Dubai Future Foundation, "The office of the future," 2016 [Online]. Available: http://www.officeofthefuture.ae/

[5] E. Dini, “d.shape,” Monolite UK Ltd, 2018 [Online]. Available: https://d-shape.com/

[6] "winsun," 2018 [Online]. Available: http://www.winsun3d.com/En

[7] C. Gosselin, R. Duballet, P. Roux, N. Gaudillière, J. Dirrenberger and P. Morel, "Large-scale 3D printing of ultrahigh performance concrete - a new processing route for architects and builders," Materials Design by ELSEVIER, vol. 100, no. 11, pp. 102-109, 2016.

[8] M. Yossef and A. Chen, "Applicability and Limitations of 3D Printing for Civil Structures," in Proceedings of the 2015 Conference on Autonomous and Robotic Construction of Infrastructure, Ames, Iowa, 2015.

[9] P. Wu, J. Wang and W. Xiangyu, "A critical review of the use of 3-D printing in the construction industry," Automation in Construction by Elsevier, pp. 21-31, 2016.

[10] L. E. Murr, E. Martinez, K. N. Amato, S. M. Gaytan, J. Hernandez and D. A. Ramirez, "Fabrication of Metal and Alloy Components by Additive Manufacturing: Examples of 3D Material Science," Journal of Material Research and Technology, pp. 42-54, 2012.

[11] I. Farina, F. FAbbrocino, G. Carpentieri, M. Modano, A. Amendola, R. Goodall, L. Feo and F. Fraternali, "On the reinforcement of cement mortars through 3D printed polymeric and metallic fibers," Composites Part B:

Engineering- By ELSEVIER, vol. 90, pp. 76-85, 2016.

[12] I. Farina, F. Fabbrocino, F. Colangelo and L. Feo, "surface roughness effects on the reinforcement of cement mortars through 3d printed metalic fibers," Composites B - by ELSEVIER, vol. 99, no. 5, pp. 305-311, 2016. 